\title{
12. The information systems academic discipline in Australian universities: a meta-analysis
}

\author{
Gail Ridley \\ IT Control Research Group \\ School of Accounting and Corporate Governance \\ University of Tasmania
}

Guy Gable

Faculty of Information Technology

Queensland University of Technology

Bob Smyth

Faculty of Information Technology

Queensland University of Technology

Shirley Gregor

School of Accounting and Business Information Systems

The Australian National University

Roger Clarke

Xamax Consultancy Pty Ltd

Canberra, Australia

\begin{abstract}
The meta-analysis chapter integrates and interprets data from earlier chapters in this monograph, drawing on the theoretical framework developed for the study. Mixed results were seen in the development of mechanisms of control and a core body of knowledge when analysis was made of information systems (IS) in Australian universities in the most recent years. The limitations on progress were related mainly to reduced IS enrolments and the associated decline in staff numbers and the autonomy of IS groups, along with the restructuring and relocation of many IS groups within universities. It appears, however, that the introduction of the Research Quality Framework (RQF) was intended to increase the quantity and quality of Australian IS research publications. While great diversity was reported regarding some
\end{abstract}


components of the body of knowledge, the existence of key IS research topics was demonstrated from a national analysis, which was not evident from analysis at a local level. Little IS theory was reported, but recognition was given to the kind of theory that was appropriate for IS. When the development of Australian IS is considered over a longer period, significant progress has been made in some mechanisms of control, including steady growth in professorial appointments. Although local contingencies were found to have had an impact on the degree of professionalism, the study was not able to confirm that these two components of the framework - responsiveness to local contingencies and degree of professionalism - were inversely related. Information systems in Australia is not likely to be unique in its development relative to other parts of the world. The study concluded that, based on IS in Australian universities, IS might be regarded as a field rather than as a discipline.

\section{Introduction}

This chapter sets out a consolidation and interpretation of data from previous chapters in this volume. By doing so it aims, in part, to present an overview of the IS academic discipline in Australian universities through the lens of the theoretical framework developed for the study by Ridley, which appears in Chapter 3 of this volume. The framework was derived from Whitley's theory of scientific change (1984a, 1984b).

An assumption behind the framework is that the development of IS in Australian universities is a response to the pressures that act on the discipline. The framework provides a common means of analysing the data collected across a range of dimensions from different regions in Australia, and presented in this monograph. As outlined in the state chapters, individual states varied in the extent of their application of and reliance on this framework.

According to the framework, the maturity of the IS discipline in Australia can be evaluated on the basis of two constructs. The first construct is the extent to which mechanisms of control have been established. Key among these are means of reputation building and a core body of knowledge. The second construct is the extent to which professionalism is able to overcome the impact of local contingencies.

This chapter applies the two framework constructs to guide analysis of data presented in previous chapters of this volume, in particular in the case studies from each state and the Australian Capital Territory (ACT). Beyond the assessment of observed data against the proposed framework, this meta-analysis seeks to draw from the Australian data some observations on observed trends and 
tensions, with an emphasis on national and international factors impacting on the status of IS in Australian universities.

\section{Approach adopted}

The first construct of the framework relates to mechanisms of control and the IS knowledge base or core body of knowledge. It is to be expected that these will increase over time with the development of the discipline. With regard to mechanisms of control, the development of a discipline depends on reputations being established and critical rewards being obtained through a range of social processes. These mechanisms of control include attracting research funding, the introduction of publication outlets and the administrative location of IS groups in universities.

A particularly important mechanism involved in the development of a discipline is the emergence of a core body of knowledge. This has four components. The first is the establishment of research and teaching methods and standards, which refers to knowledge gain and transfer. The second component, a unique symbol set, enables unambiguous communication between initiates in the discipline and, in the process, prevents other disciplines trying to subsume the area into their own. The third component, key research and teaching of IS topics, sets out the knowledge domain, while the fourth component, laws, rules and evidenced guidelines, refers to the knowledge types required in the discipline.

The second framework construct concerns the degree of professionalism of the discipline, or accepted ways of undertaking IS research and teaching, and the extent to which it enables the community to withstand the impact of local contingencies. It is postulated that where a discipline is not highly professionalised, local contingencies such as political pressures have high impact. Consequently, the degree of professionalism of IS is suggested by the extent of variation in the nature of its research and teaching across the 'states' of Australia and over time.

It is argued that an examination of progress in the constructs and their components will reveal the nature and development of the IS academic discipline in Australia. This chapter reports on that examination, through a meta-analysis of the data collected and reported elsewhere in this volume. This analysis draws initially on points of similarity and difference from the 'state' case studies, and their relationship to the framework.

The framework constructs and their components guided the development of a protocol for the state reports in this volume (Gable 2006). The analysis presented below utilised data gathered in seven broad topic areas embodied in the common case-study protocol. The broad topic questions were:

- What is the relative size of the IS presence at the university? 
- What is the administrative placement of IS (including changes over time)?

- To what extent has IS at the university been impacted on by local contingencies?

- To what extent is IS identified as a separate field at the university?

- What are the distinctive features of the IS curriculum at the university?

- What are the distinctive features of IS research at the university?

- Who are the key people who have had an impact on IS in universities in the state?

The middle five topics were designed to gather data for evaluation of the framework, while the first and the last topics listed provided complementary information. The key people who have had an impact on IS in the states are not addressed in this chapter, as this has been presented in detail in the previous chapters through vignettes - and these data do not lend themselves to aggregation.

Thematic analysis was undertaken of the state reports presented in this volume (Dixon-Woods et al. 2005). Beyond reporting on the similarities and differences across the states from the perspective of the framework, the meta-analysis also aggregates the findings to provide an Australian perspective. This meta-analysis chapter comments further on several significant issues that lie outside the guiding framework.

\section{Size of the IS presence in Australian universities}

The starting point in the meta-analysis is an examination of the size of the IS presence in Australian universities. It is hypothesised that the size of the IS presence can be related to the mechanisms of control for IS in Australian universities. For example, where there are few staff, or where the student/staff ratio is high, it is likely to be more difficult for staff to demonstrate mechanisms of control, such as engagement in research that is able to attract research funding, or involvement in the introduction or management of IS publication outlets.

Table 12.1 lists the 39 universities in Australia - 37 public and two private (Bond and Notre Dame). Marginson and Considine (2000) characterised the public universities as 'Sandstones', 'Redbricks', 'Gumtrees', 'Unitechs' and 'New Universities'. The six Sandstones were founded in Australia before World War I. The three Redbricks were founded in the 1940s and 1950s. The 10 Gumtrees are postwar and pre-Dawkins general universities founded between the early 1960s and mid-1970s. The five Unitechs are former large institutes of technology formed post-Dawkins. The $13 \mathrm{New}$ Universities are other post-Dawkins universities, often formed out of colleges of advanced education; several New Universities are specialist regional and/or distance-education providers. 
Table12.1 Australian universities by state within era

\begin{tabular}{|c|c|c|c|c|c|}
\hline \multirow{2}{*}{\multicolumn{2}{|c|}{$\begin{array}{c}\text { Era/university } \\
\text { Sandstones (pre-World War I) }\end{array}$}} & \multirow{3}{*}{$\begin{array}{l}\text { State } \\
\text { NSW }\end{array}$} & \multicolumn{2}{|c|}{ Unitechs (former institutes of technology) } & \multirow{3}{*}{\begin{tabular}{|l|} 
NSW \\
Qld
\end{tabular}} \\
\hline & & & \multirow{2}{*}{\begin{tabular}{|r|}
20 \\
21
\end{tabular}} & \multirow{2}{*}{\begin{tabular}{|l|}
$\begin{array}{l}\text { University of Technology, Sydney } \\
\text { (UTS) }\end{array}$ \\
$\begin{array}{l}\text { Queensland University of Technology } \\
\text { (QUT) }\end{array}$ \\
\end{tabular}} & \\
\hline 1 & University of Sydney & & & & \\
\hline 2 & University of Queensland (UQ) & Qld & 22 & University of South Australia (UniSA) & SA \\
\hline 3 & University of Adelaide & SA & 23 & RMIT University & Vic \\
\hline 4 & University of Tasmania (UTAS) & Tas & 24 & Curtin University of Technology & WA \\
\hline 5 & University of Melbourne & Vic & \multicolumn{2}{|c|}{ New Universities (post-1987) } & \\
\hline 6 & University of Western Australia (UWA) & WA & 25 & University of Canberra & ACT \\
\hline \multicolumn{2}{|c|}{ Redbricks (1940-50s) } & & 26 & Australian Catholic University (ACU) & multi \\
\hline 7 & $\begin{array}{l}\text { The Australian National University } \\
\text { (ANU) }\end{array}$ & ACT & 27 & Charles Sturt University (CSU) & NSW \\
\hline 8 & $\begin{array}{l}\text { University of New South Wales } \\
\text { (UNSW) }\end{array}$ & NSW & 28 & Southern Cross University (SCU) & NSW \\
\hline 9 & Monash University & Vic & 29 & University of Western Sydney (UWS) & NSW \\
\hline \multicolumn{2}{|c|}{ Gumtrees (1960s to mid-1970s) } & & 30 & Charles Darwin University (CDU) & NT \\
\hline 10 & Macquarie University & NSW & 31 & Central Queensland University (COU) & Old \\
\hline 11 & University of New England (UNE) & NSW & 32 & $\begin{array}{l}\text { University of Southern Queensland } \\
\text { (USQ) }\end{array}$ & Qld \\
\hline 12 & University of Newcastle & NSW & 33 & $\begin{array}{l}\text { University of the Sunshine Coast } \\
\text { (USC) }\end{array}$ & Qld \\
\hline 13 & University of Wollongong (UoW) & NSW & 34 & University of Ballarat & $\mathrm{VIC}$ \\
\hline 14 & Griffith University & QLD & 35 & Swinburne University of Technology & VIC \\
\hline 15 & James Cook University (JCU) & QLD & 36 & Victoria University (VU) & $\mathrm{VIC}$ \\
\hline 16 & Flinders University & SA & 37 & Edith Cowan University (ECU) & WA \\
\hline 17 & Deakin University & VIC & \multicolumn{2}{|c|}{ Private } & \\
\hline 18 & La Trobe University & VIC & 38 & Bond University & QLD \\
\hline 19 & Murdoch University & WA & 39 & Notre Dame University & WA \\
\hline
\end{tabular}

The number of universities identified in the seven regions varied from a single university in Tasmania to 10 in the most populous state, New South Wales (NSW). Although Tasmania has the smallest population of the six Australian states, the Australian Capital Territory has a smaller population again. Three campuses of the one university service Tasmania, while the Australian Capital Territory has three universities. The number of IS groups in universities in the regions (more than one IS group was reported in several universities) ranged from one in Tasmania to 10 in New South Wales. From Table 12.2, it can be seen that the size of the IS presence in each university (staff and students) varied considerably. It is important to note that the numbers in Table 12.2 are very much in flux, representing a consolidation of indicative data gathered over a period when IS was in the process of major change. The NSW figures are also notably incomplete. Hence, the values in the table should not be regarded as precise. In spite of the acknowledged limitations in precision of the figures, it is felt that some meaningful differences and broad trends can be discerned from the numbers in Table 12.2. 
Table 12.2 Size of IS presence in Australian universities

\begin{tabular}{|c|c|c|c|c|c|c|c|}
\hline Attribute & WA & SA & Tas & Vic & ACT & NSW & Old \\
\hline 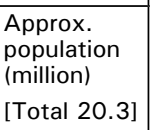 & 2.0 & 1.5 & 0.5 & 5.0 & 0.3 & 7.0 & 4.0 \\
\hline $\begin{array}{l}\text { No. IS } \\
\text { groups/ } \\
\text { universities }\end{array}$ & $4 / 5$ & $2 / 3$ [?] & $1 / 1$ & $9 / 9$ & $3 / 3$ & $10 / 13$ or 14 & $11 / 9$ \\
\hline $\begin{array}{l}\text { Total } \\
\text { approx. IS } \\
\text { staff } \\
\text { [Total 751] }\end{array}$ & 57 & 15 & 11 & 391 & 25 & \begin{tabular}{|l} 
Not \\
provided
\end{tabular} & 135 \\
\hline $\begin{array}{l}\text { IS staff per } \\
100 \text { 000 of } \\
\text { population } \\
\text { [Mean } 3.7 \text { ] }\end{array}$ & 2.9 & 1.0 & 2.2 & 7.8 & 8.3 & 1.7 & 3.4 \\
\hline $\begin{array}{l}\text { Total } \\
\text { approx. IS } \\
\text { students } \\
\text { [Total c. } 18 \\
500]\end{array}$ & $\begin{array}{l}480 \text { UG } \\
345 \text { PG }\end{array}$ & $>2000$ & $\begin{array}{l}>1000 \\
(800 \\
\text { EFTSU) }\end{array}$ & 7000 & 450 & $\begin{array}{l}\text { Not } \\
\text { provided }\end{array}$ & 5400 \\
\hline $\begin{array}{l}\text { IS students } \\
\text { per } 100000 \\
\text { of } \\
\text { population } \\
\text { [Mean 125, } \\
\text { excl. NSW] }\end{array}$ & $\begin{array}{l}24 \text { UG } \\
17 \text { PG }\end{array}$ & $>133$ & $\begin{array}{l}200 \\
(160 \\
\text { EFTSU })\end{array}$ & 140 & 150 & $\begin{array}{l}\text { Not } \\
\text { provided }\end{array}$ & 135 \\
\hline $\begin{array}{l}\text { Raw ratio } \\
\text { student/staff }\end{array}$ & 14.5 & $>133$ [?] & 90 [?] & 17.9 & 18 & $\begin{array}{l}\text { Not } \\
\text { provided }\end{array}$ & 40 [?] \\
\hline $\begin{array}{l}\text { Enrolment } \\
\text { trend }\end{array}$ & $\begin{array}{l}\text { Severe } \\
\text { decline }\end{array}$ & $?$ & Decline & & \begin{tabular}{|l|} 
ADFA \\
growth in \\
PhD, \\
course-work \\
Masters \\
\end{tabular} & & $\begin{array}{l}\text { Downturn in } \\
\text { course } \\
\text { demand }\end{array}$ \\
\hline $\begin{array}{l}\text { Staff no. } \\
\text { trend }\end{array}$ & $\begin{array}{l}\text { Staff } \\
\text { reductions }\end{array}$ & $?$ & $\begin{array}{l}\text { Some } \\
\text { attrition }\end{array}$ & \begin{tabular}{|l|} 
Staff cuts \\
Monash, \\
Victoria Uni
\end{tabular} & & & $\begin{array}{l}\text { Staff } \\
\text { reductions }\end{array}$ \\
\hline $\begin{array}{l}\text { Other } \\
\text { aspects } \\
\text { relating to } \\
\text { size of IS } \\
\text { presence }\end{array}$ & $\begin{array}{l}\text { Strong in } \\
\text { post-1987 } \\
\text { unis; limited } \\
\text { in others }\end{array}$ & \begin{tabular}{|l|} 
Significant \\
presence \\
only in \\
post-Dawkins \\
uni
\end{tabular} & \begin{tabular}{|l|} 
Fourth-largest \\
school at \\
UTAS in \\
2005
\end{tabular} & $\begin{array}{l}\text { Strong staff } \\
\text { and student } \\
\text { nos across } 9 \\
\text { unis }\end{array}$ & $\begin{array}{l}\text { Strong IS } \\
\text { staff } \\
\text { numbers } \\
\text { relative to } \\
\text { uni sizes }\end{array}$ & \begin{tabular}{|l|} 
Strong at \\
UNSW and \\
UTS; \\
small-medium \\
at other unis
\end{tabular} & $\begin{array}{l}\text { Strong at } \\
\text { QUT, } \\
\text { Griffith and } \\
\text { UQ; } \\
\text { particularly } \\
\text { strong } \\
\text { relative to } \\
\text { uni size at } \\
\text { CQU and } \\
\text { USO }\end{array}$ \\
\hline
\end{tabular}

Although a few universities had no IS presence, some universities had multiple IS groups. As expected, larger universities were those most likely to have multiple IS groups. Although the data are incomplete, it can be seen that all universities in some states had an IS presence, while this was not the case in Western Australia and South Australia, and most noticeably not the case in New South Wales.

From the number of IS staff and students reported, it appears that a considerable variation in both exist across the universities. Some inconsistencies, however, in the way that the figures for both were reported across the regions could affect the extent to which conclusions can be drawn. For example, whether the staff members reported were full-time or part-time, and included support staff, might 
not be consistent from one region to another. Similarly, student numbers reported from the states might not be reported on a consistent basis, as some could relate to student numbers studying IS, student numbers undertaking an IS major, or equivalent full-time student units (EFTSU). To allow for possible inconsistencies, only broad patterns will be discussed.

The authors of the Queensland case study suggested that the number of IS academics was a better guide to the size of the IS presence than other characteristics. If this is the case - and even if the count is normalised against population - it is apparent that Victoria is the Australian region with the greatest IS presence. Victoria had about three times the number of IS academic staff reported in the region with the next highest number, which was Queensland, although in New South Wales not all universities were canvassed. A large variation was seen in the number of staff in different IS groups. The Australian Catholic University was reported to have just three IS staff, while a total of 92 staff was reported at the Royal Melbourne Institute of Technology (RMIT) University.

The number of IS students also varied considerably within and across the states. The Australian Catholic University reported just 76 IS students, while there were up to 1000 IS students each at Monash University and the University of Ballarat.

Considerable variation was also seen in the ratio between the number of IS staff and the number of IS students. This characteristic is very likely to impact on teaching loads and therefore research outputs and other aspects relevant to mechanisms of control. Some states appeared to have an over-representation of IS staff for the student numbers reported-for example, in Western Australia, Victoria and the Australian Capital Territory - while the reverse was indicated in other states - for example, South Australia and Tasmania. Some of the differences could be accounted for by different approaches to delivery of courses to offshore students. For example, the majority of the IS students reported for Tasmania were offshore. Although Australian staff are involved in delivery to offshore IS students, there are, however, also offshore staff not employed by the University of Tasmania who are excluded from the figures.

The study was undertaken in the aftermath of the 'dotcom implosion' about 2000. It was therefore unsurprising that many states reported declines in student and staff numbers in recent years. All interviewees in Western Australia reported both declines. The authors of the Tasmanian and Queensland chapters referred to reduced enrolments, while Victoria reported IS staff cuts at two of its large universities. South Australia commented in particular on a decline in local student enrolments. Western Australia reported declining enrolments in specialist IS programs, local students and postgraduate students. Queensland predicted that the demand for IS places in universities in that state would lag behind the demand 
for IS practitioner skills. Reference was made to the difficulty of attracting research students to one university that was not located in a state capital. The Australian Defence Force Academy (ADFA), however, had experienced growth in $\mathrm{PhD}$ and graduate course-work enrolments. It is too early to know whether the declines in student and staff counts have been a lengthy lull or a shift to a new and considerably lower plateau.

The raw student/staff ratios calculated from the data provided in several of the state reports are anomalous. This presumably arises from distinctly different definitions of student counts adopted (enrolled count versus EFTSUs). Comments arising from Table 12.2, however, provide some assistance in explaining some of the variation in the ratio between student and staff numbers in the different regions. In particular, a strong IS presence was reported in some universities in Queensland relative to the size of the university (Central Queensland University and the University of Southern Queensland), although in general in that state the IS presence was consistent with the size of the university. The West Australian case reported that the post-Dawkins (post-1987) institutions in that state had a strong IS presence, while it was more limited at the other universities. Like Western Australia, New South Wales reported a strong IS presence at some universities (the UNSW and the UTS), with a smaller presence at the others. The ACT report commented on the generally strong IS staff numbers relative to the size of the universities, as did Victoria. The ACT report highlighted the strong staff numbers relative to student enrolments, which was apparent in the comparison made against the other states, and was seen also in Western Australia and Victoria. Although Tasmania reported that the School of Information Systems was the fourth-largest school at the University of Tasmania in 2005, by 2007, its presence had declined and it merged with the School of Computing at the start of 2008.

\section{Summary}

Analysis in this section indicates that the majority of universities in Australia contained at least one IS group, suggesting that IS has broad acceptance in Australia as an area that needs representation in university teaching and/or research programs. As not all universities contain an IS group, however, IS is not considered universally throughout Australia to be an essential teaching and/or research area. The number of students and IS staff varied a great deal within Australian universities with an IS group. While this characteristic might be accounted for in part by variations in university size, large variations in the staff/student ratio suggest that other forces are also at play, as the regions could be categorised largely into those with a high and those with a low staff/student ratio. Cross-state analysis also revealed a general decline in IS student enrolment in Australian universities in recent years, particularly for domestic students, with consequent reductions in staff numbers. 


\section{Mechanisms of control}

The theoretical framework's first construct includes mechanisms of control. Control of resources, curriculum and research is seen to derive from the increasing autonomy of IS groups. The autonomy of IS academic groups and, therefore, their structural location in universities can also be used to evaluate the extent to which IS academic groups are able to control critical rewards.

This construct also reflects the dependence of academics on the development of prestigious reputations for individuals and groups, leading to the control of critical rewards (Whitley 1984a). Reputation building and critical rewards are attained through publication records and attracting research funding (Mingers and Stowell 1997), the development and management of publication outlets and similar processes.

\section{Publication records}

In comparison with some other disciplines, the research output of IS was seen as being generally lower. One possible explanation offered is that many IS academics have entered academia from a practitioner background rather than a researcher background.

Research output was, however, considered to have increased in recent years in Victoria and the Australian Capital Territory, reflecting increased effort and productivity. Although Tasmania reported a focus on conference proceedings, in Victoria incentives for publications were linked increasingly to journal rather than conference publications. Queensland also reported a growing preference for journal publications, even when compared with prestigious conferences, which could relate to the planned introduction of the RQF, which is discussed later. Some universities, including those in Western Australia, reported considerable numbers of PhD students, including 20 at the UniSA, which could be expected to bolster the publication records of those schools.

Different factors, however, were reported in some universities. Researchers at Charles Sturt University identified little with IS. In some IS groups in New South Wales, the Australasian Conference on Information Systems (ACIS) and the International Conference on Information Systems (ICIS) were not universally considered central conferences for the discipline. Also in New South Wales, some interviewees found it difficult to agree on a definition of IS.

The Australasian Journal of Information Systems (AJIS) is a core local IS journal; however, no reference was made in any state report to the development of any additional Australian IS publication outlets.

\section{Attracting research funding}

Analysis indicated that IS academics have found it difficult to gain research funding, particularly funding from the prestigious Australian Research Council 
(ARC). As reported in the retrospective chapter, the ARC coding scheme for many years omitted IS, forcing bids to be made within either business or computer science codes - with the result that they were evaluated by assessors who were often unfamiliar with IS.

Academics in Victoria reported that research funding was 'dwindling'. The limited success reported for IS in attaining ARC funding contrasts with the greater success of the computing discipline. More emphasis on research funding from industry, internal university sources or from research centres was noted by ADFA, the U Tasmania and in Victoria. The low proportion of IS staff holding a PhD at some Australian universities, such as at the UTS, or completing one, would act to limit opportunity to apply and gain research funding, particularly from the ARC, where track record is of major importance

\section{Structural location and independence of IS groups}

Information systems was seen to have little autonomy in some universities, such as at the UTS, where IS courses were integrated with computing courses.

Many examples were provided where IS groups were dependent on the outcomes from other disciplines. Several states, including Victoria, reported IS groups that delivered teaching within non-IS programs. As an example of common delivery arrangements found in Australian IS, the IS group at the University of Sydney delivers an introductory IS unit to 1000 students in the Bachelor of Commerce degree, while at the UniSA an even greater number of students studied an IS unit within a Bachelor of Commerce. The IS groups at all universities in New South Wales, other than at the UNSW, were dependent on enrolments in other programs and on the number of compulsory IS units in those programs. To counter the disadvantages of such dependence on other disciplines, the substantial financial rewards from teaching large service classes have been seen as a means for IS groups to 'subsidise' the running of small specialist IS classes.

It was suggested in the Queensland chapter that IS groups had a greater level of academic control and prestige where they had a separate identity in the university structure. The findings from Western Australia were consistent with this perspective, as the IS groups that were considered to be a subset of other disciplines in their structural location in the university had lower status. In Victoria, however, no correlation was seen between having a separate structural identity in a university and the perception by IS academics of having greater status.

Information systems groups are located in a diversity of faculties. In Victorian universities, although most IS groups were based in science or business, others were located in arts, law, engineering, communication and health science faculties. Variability was noted similarly in the home faculty for IS groups in 
Queensland. The Queensland report commented that often the IS groups that had moved out from business faculties were highly autonomous

The Queensland chapter commented on a remarkable variation in the location of IS staff in the university structure. In New South Wales, fragmentation of IS staff was reported across different departments and faculties, particularly in science and computing, where most IS groups were ad hoc or informal groups within larger departments, with little interaction among the IS groups. As an example of this characteristic, at Macquarie University there was an ad hoc IS group in computing, while other IS groups existed also in accounting and management, and information management was taught in statistics. Other examples were given in which IS was one component of a school that represented a different discipline, such as at the UniSA.

A range of consequences was identified arising from IS not being seen as having a separate identity in the university structure. It was reported that the wider university communities in New South Wales did not see IS as a separate field. Some IS groups might not have identified themselves in this way either. For example, at the University of Adelaide, where there were only three IS staff and IS degrees were not offered, the staff were not aware of current issues for IS groups at other institutions. In three of the nine universities in Victoria, IS was not seen as having attained a separate identity. In some states, it was reported that there were few strongly identified IS programs; for example, in New South Wales, only the UNSW was seen as having a strongly identified IS program. In one Victorian university, IS staff perceived that IS journals and conferences had not been included in the ranking exercise of their department. Variety in the nomenclature adopted for IS courses was seen, while IS was not offered as a degree at some universities, including at Flinders University.

Queensland reported that many IS groups had restructured or planned to do so during 2004-06, as a result of reduced demand from students for IT courses. The same state reported two different trends regarding changes to the structural placement of IS groups in that state. Information systems groups at Central Queensland University, Griffith University and the Queensland University of Technology had, before this study, moved to separate IS schools, while the IS groups from the University of Southern Queensland and Bond University at the time of the study were relocating to business. The IS school at Edith Cowan University merged with management in 2007, while at the University of Tasmania, the School of Information Systems in the Faculty of Business merged with the School of Computing into a Faculty of Science, Engineering and Technology in 2008. Queensland noted that reduced autonomy of IS groups was associated with the more recent decline in student demand for IS programs, as seen also in Tasmania. 
The NSW report noted that of the 10 universities with IS groups in New South Wales, the main IS group at only three included IS in their name. Not being identified with IS by name would also act to reduce the identity of these IS groups.

In New South Wales, a perception was reported that regional universities were less threatened by the decline in IS student demand reported elsewhere, and felt less need to conform with research trends. Certainly, a subset of regional universities reported a disproportionately strong IS presence, associated with positioning of the institution to emphasise external studies and the development of multiple campuses away from the home campus. Two Queensland regional universities, Central Queensland University and the University of Southern Queensland, showed these characteristics.

After the initial state case studies, further data were gathered to assess the extent to which 'business' or 'technology' predominated in the administrative placement of IS groups in Australian universities. In addition, an analysis was made of the administrative placement of IS groups in relation to the era in which each university was established. The concept of categories of university types associated with different eras is discussed earlier in this chapter, in relation to Table 12.1.

Table 12.3 summarises the placement of IS at Australian universities. 'Business' includes faculties that are called business, economics or commerce. 'Technology' includes faculties that are called science, IT or engineering. 'Both' refers to universities that have an IS group in the 'business' and the 'technology' faculty types. 'Combined' is where the university has a combined faculty called something like 'business and technology'. 'Other' indicates that IS is situated in some other type of faculty, such as arts.

From Table 12.3, we note that IS is located within business at 17 universities, in technology at 11 and in 'other' at two. At five universities, IS exists in business and technology, and in four universities IS resides in a combined business-technology area. Information systems is located solely in business in 44 per cent of universities (17), solely in technical in 28 per cent of universities (11), in business or business and technical (17 plus five) in 56 per cent of universities, in technical or technical and business ( 11 plus five) in 41 per cent of universities. Broadly, we observe an approximately $60 / 40$ ratio of business versus technical. 
Table 12.3 IS placement relative to university era/type

\begin{tabular}{l|c|c|c|c|c|c}
\hline Era & Business & Tech & Both & Combined & Other & Total \\
\hline Gumtree & 4 & 3 & 2 & & 1 & 10 \\
\hline Unitech & 2 & 3 & & & & 5 \\
\hline Sandstone & 3 & 1 & 2 & & & 6 \\
\hline Redbrick & 2 & 1 & & & & 3 \\
\hline New & 5 & 3 & 1 & 3 & 1 & 13 \\
\hline Private & 1 & & & 1 & & 2 \\
\hline Count: & 17 & 11 & 5 & 4 & 2 & 39 \\
\hline
\end{tabular}

Note: Several universities have more than one IS group in the same faculty type - for example, Deakin has IS groups in the School of Information Systems and the Deakin Business School, both of which are within the Faculty of Business and Law. ADFA was not included in the count.

We note further that IS is located within business relatively more often for all but one of the six 'eras', with IS located more often in technical only at the Unitech universities. Information systems at the Sandstones is generally associated with the Faculty of Commerce/Business/Economics. In two of the three Redbrick universities (the ANU and the UNSW), the main concentration of IS seems to be in the Faculty of Economics/Commerce. The other Redbrick, Monash, has a Faculty of Information Technology in which IS is sited. Although ADFA is a college of the UNSW, IS there is located within a school of technology. Three of the five Unitechs (the QUT, UTS, UniSA) have faculties/divisions of IT in which IS is concentrated. At the other two 'Unitechs' (Curtin and RMIT), IS is associated with business.

There is little pattern to the placement of IS at the Gumtrees universities; four have IS situated in business-type faculties, three in technology faculties and two (Macquarie and Griffith) have IS groups in both types of faculty. Information systems groups are associated most often with business at the New universities. There seems, however, to be a trend towards the creation of a faculty that combines business and informatics/computing at some of these universities. Three of the New universities have this type of combined faculty.

\section{Other ways of attaining prestigious reputations}

In Queensland and elsewhere, numbers of IS academics had achieved increased status in their universities, with the professorial staff total having increased considerably in the past two decades. These staff had similar levels of influence as did professorial staff in other disciplines.

The achievement of IS professorial staff was seen as a crucial step in the enhancement of the reputation of an associated IS group in a university, while IS groups without professorial staff were seen to have a lower profile in their university.

An industry-based Chair in Business Information Systems was appointed at the UniSA in 2006. In addition to local professors, the UniSA also appointed two IS 
adjunct professors from Europe, which contributed to the reputation of the IS group at that university. It was seen that some professorial appointments had taken place only relatively recently. At the ANU, the first IS professor was appointed only in 2000, which suggests a restricted profile for IS at that university until that year. Also noteworthy is the late emergence of departments and chairs at the University of Melbourne, in 1996, and at the University of Sydney, in 2002. There are no professors in IS at two Sandstone universities - Adelaide University and the UWA.

Appendix 2.4 in the 'retrospective' chapter, Chapter 2, identified a total of 69 individuals who had been identified as having held chairs in IS during the period 1974-2007, in 31 of a total of approximately 42 institutions. When people who have held multiple successive professorships are counted, the total is 82 . In early 2007, there appeared to be 52 IS professors in 28 institutions. The period 1974-2007 was examined. Building on the steady progress made from 1990 to 1997, considerable growth took place between 1998 and 2004 inclusive, during which time more than 60 per cent of the IS professorial appointments occurred.

A number of senior IS academics had taken on other significant and prestigious roles with recognition beyond IS, particularly since about 2000. In the 1990s, IS researchers had little input into ARC panels; however, in more recent years, a number of senior IS academics had become expert assessors for the ARC, while one had acted as an advisor to the Australian government on IT and national research priorities. In the past five or six years, there has been a concerted effort by the Australasian Chapter of the Association for Information Systems (AAIS) and the Australian Council of Professors and Heads of Information Systems (ACPHIS) to have IS representation on the ARC MICS Panel (the panel that is likely to assess the majority of IS ARC grant applications). Janice Burn, Graeme Shanks and Michael Rosemann have been IS representatives on the MICS Panel; however, Rosemann's term ends in December 2007, and the AAIS/ACPHIS nomination for 2008-09 was unsuccessful.

As a further example of Australian IS academics gaining national and international status, while at the University of Queensland, Ron Weber was named as the first president from Region 3 of the Association for Information Systems (AIS), and was also the 2001 Co-Chair of ICIS and the 2001 Chair of the ICIS Executive Committee. Weber also received the Prime Minister's Award for University Teacher of the Year in 2000, and was the first non-US resident to hold the position of editor-in-chief of MIS Quarterly. Shirley Gregor from the ANU was awarded an Order for Australia in 2005 and became the Director of the Professional Standards Board for the Australian Computer Society (ACS) in 2007. Alan Underwood developed the core body of knowledge used by the ACS when accrediting IT courses in Australian institutions. In 2007, Ed Lewis from the 
Australian Capital Territory chaired the IT-030 Committee for Standards Australia. All these roles enhance the reputation of IS groups, and the IS field.

\section{Summary}

This section considered the autonomy of IS academic groups from their structural location in universities, and the associated extent to which IS academic groups controlled critical rewards. Although the research output of IS schools was perceived as low in comparison with other disciplines, effort was being made in many IS groups recently to increase research output and to publish in journals rather than in conference proceedings. Although research funding within IS was seen as difficult to obtain - particularly ARC grants - at least one IS group reported increasing success. The independence of IS groups in Australian universities varied considerably, with some being dependent on the enrolment and structure of programs in other disciplines. While most IS groups were found in science or business faculties, many other structures were reported. Although some IS groups had strongly identified programs, and delivered IS degrees, often IS groups were fragmented across departments and faculties, which reduced opportunities for those groups to control critical rewards. Although the number of professorial appointments and the attainment of other prestigious roles for senior IS academics that had an impact outside IS had increased significantly since about 2000, it was hard to generalise about the achievement of mechanisms of control for IS in Australia. This is because the diversity in arrangements is considerable, with significant autonomy experienced by some IS groups, but with little in others. Reduced student numbers have, however, placed pressure for restructuring on IS groups in recent years, which, in turn, has eroded autonomy for IS in Australian universities.

\section{Core body of knowledge}

In the theoretical framework that guides this meta-analysis, the first construct proposed included a core body of knowledge, comprising the four components: research and teaching methods and standards; a unique symbol set; key research and teaching IS topics; and laws, rules and evidenced guidelines. Each component will be considered in turn below, by reviewing the data derived from the case studies presented in this monograph.

\section{Research and teaching methods and standards}

The theoretical framework underpinning this study suggests that a discipline will show consensus in research and teaching methods and standards. The degree to which this holds for IS groups in Australian universities will be examined next, using data from the case studies from each of the seven regions. 


\section{Research}

Diversity of research methods was reported in many of the regions, including in Western Australia and Queensland. The reason for research diversity was accounted for in a range of ways, including being driven by staff research interests, by the nature and requirements of grant funding sought or obtained and appointing new staff who had existing research interests. Other IS staff saw the diversity in research methods as a response to the $\mathrm{RQF}$, a proposed Australian government approach that linked the allocation of research funding to Australian universities with an assessment of research quality. A shortage of supervisory capacity was reported at the University of Canberra, which intended to restrict the future number of IS PhD students at that university. This characteristic was expected to impact on that university's capacity to attract government funding for research, as the RQF proposed to link the allocation of some research funds to PhD completions. An IS group's publication output would also be affected by limited PhD numbers.

In Victoria, IS research was seen to be predominantly interpretivist, and aligned more to European approaches than to those from North America. Consequently, diverse blended approaches to research were not reported as common in IS research in Victoria, which was interpreted by the authors of the case study from that state as inconsistent with practice in mature disciplines.

Diversity of research administration was also reported. For example, in Queensland universities, no consistent patterns were seen in the organisational approaches taken to promote IS research. Strategies that were evident ranged from the formation of formal research groups and research centres to voluntary collaboration initiated by researchers. Research undertaken in Queensland universities varied from those having a tight IS focus to others where broad interdisciplinary collaboration was evident. NSW universities commented that there were few large IS research projects, and research activity was fragmented and diverse.

In contrast, the ANU reported an increased quantity and quality of IS research in recent years, and recognised plurality in research methods. Universities from several Australian regions referred to research seminars that were held regularly, and the ANU reported that it hosted a biennial workshop on 'IS foundations'.

\section{Teaching}

Relatively few comments on teaching methods and standards were made in the reports from the seven regions. WA universities reported much variety in teaching methods and standards, while in the Australian Capital Territory, lectures, seminars, tutorials, group projects, case studies, presentations, use of online learning management systems (WebCT) and laboratory sessions were used for IS delivery. 
As suggested earlier, where an IS group teaches IS within another degree or discipline, it is likely to have limited control over delivery. A number of IS groups referred to delivering an introductory IS unit to large numbers of students in a commerce or business degree. As an example of the restrictions such an arrangement could impose, at the UniSA, where IS is taught in association with an accounting program, CPA accreditation determines not only the content, but the standards of the teaching.

Distance-education methods are used in some universities for the delivery of IS, including at the NSW regional university, Charles Sturt, and at the University of Southern Queensland. At ADFA, most postgraduate course-work programs are taught through distance education, using WebCT until 2007, and then ILIVE from that year. Other IS groups referred to the delivery of their programs using WebCT.

The applied nature of IS is reflected in some of the IS delivery styles and requirements for teaching. For example, at the University of Canberra, tutors and guest lecturers are often appointed from industry, while ADFA uses 'problem-based learning'. At the UTS, all IS students were required to undertake work experience before graduation, until 2002, which resulted in the students either studying part-time or in a 'sandwich' mode that interwove study and professional work experience. A different approach to ensuring that graduates of IS programs were equipped to apply their learning in the workplace was referred to by the University of Canberra and the University of Tasmania; both taught interpersonal and group skills through group projects, role-plays, case studies and similar methods.

Several universities reported high numbers of international students, including those located offshore. Such arrangements necessitate changes to delivery arrangements. For example, the University of Tasmania used local staff and visiting staff from Australia to deliver its IS programs in Shanghai.

\section{Summary}

Diversity of research methods and standards was seen in IS groups across Australian universities. Approaches to administering IS research were also varied, with a lack of consensus on research methods and standards. Many regions regarded the lack of consensus on research approaches as an indicator of restricted progress in the development of IS. At least one region, however, considered that having a single predominant research approach suggested a lack of maturity for IS. Limited data on teaching methods and standards hamper the interpretation that can be made in this area. Some evidence was seen of matching delivery methods to the applied nature of IS; however, other teaching methods and delivery styles appeared to be in part an outcome of mechanisms adopted for pragmatic reasons to compensate for declining IS enrolments and staff reductions. 
Arrangements made for offshore delivery, distance education, use of online learning management systems and IS delivery in non-IS programs or disciplines might be examples of this characteristic.

\section{Unique symbol set}

Although relatively few comments were made by the authors of each state report regarding whether a unique symbol set existed for IS in their universities, the comments made were remarkably consistent.

In Western Australia, IS was seen as an area that could be transposed readily from one discipline grouping to another, while at the University of Canberra there was a history of integration of IS with other information and communication technologies (ICTs). Both characteristics suggest that IS does not have a unique symbol set. At the University of Adelaide, the placement of IS in a school of commerce acted to dissipate shared assumptions and language. Information systems staff of the University of Adelaide did not believe that IS had its own terminology, as IS was seen as a bridge between business and computing. Staff at the University of Tasmania also believed that IS terminology was broadly familiar to business and computing academics, while some ACT IS groups accepted the commonalities with allied fields such as software engineering and computing. The Queensland report found no evidence of a unique symbol set, attributing this to the diversity in the content of the curriculum and research topics.

The ACT report noted with concern that much of the symbol system of IS was used also by application areas when using IS and IT as tools. Consequently, people from outside IS feel able to teach IS within their own areas, as there is little barrier to doing so posed by a unique symbol set. The problem is compounded further by a poor understanding from outside IS of the meaning of information systems, and continuing debate within IS about how to define the discipline.

\section{Summary}

Australian IS staff members believe that IS has no unique symbol set. Information systems terms are used by related disciplines such as business and computing, and also for teaching in application areas by those not associated with IS. Consequently, IS is not able to exclude outsiders from its domain through use of an IS symbol set as a barrier, or to clearly delineate its boundaries. Both characteristics suggest that IS will experience continued incursions on its borders.

\section{Key IS topics in research and teaching}

The theoretical framework for this study suggests that key research and teaching topics will become more consistent as the IS discipline develops. This section evaluates the degree to which consensus exists on the key IS research and 
teaching topics in Australian universities, using the considerable evidence provided in the state reports.

\section{Key IS teaching topics}

Circumstances surrounding IS teaching that impacts on the topics taught are considered first. It is acknowledged that the structural placement within which the IS teaching is undertaken affects the teaching topics. For example, the NSW authors commented that the least distinctive IS curriculum was found in IS support classes in commerce, and some IS groups were required to conform to CPA accreditation requirements when delivering IS within accounting programs. The integration of IS with other areas for teaching at the University of Canberra affected the topics taught. To illustrate, the co-location of IS with computing at that university resulted in the integration of the two fields, which meant that IS curriculum was not presented in a theoretical way, but in an applied way. In South Australia, relocating IS within the university brought about a re-examination of how IS courses related to IT and computing.

The nature of the degree programs and the organisational location of the IS staff influence the IS topics taught. Victoria identified the trend that from about 2004 students preferred to enrol in a double degree, one of which was IS, while before this time there was greater preference for a single IS degree, such as a Bachelor of Information Systems. Victoria also commented on a big increase in IS and IT course-work Masters degrees in the past decade. A wide range of IS programs was noted in Queensland. Other influences on IS teaching topics were also identified. For example, at the University of Canberra, many of the students were Australian government employees.

Numerous IS groups, including those at the UniSA and in Queensland universities, pointed to broad and diverse teaching topics. Victoria reported a diversity in IS degrees and their curricula, which made it challenging to identify an IS core body of knowledge. Consequently, few key teaching topics could be identified across programs or units in Victoria. The Queensland report suggested a reason for the variety in IS teaching topics in its universities. The Queensland authors identified a lack of consistency regarding the boundary for curriculum content between IS and related areas, and therefore the core body of knowledge. For example, databases and web-related topics are sometimes considered to be included within IS, while elsewhere they are seen as falling outside of IS.

Some states and universities were able to identify principles that guided the development of IS teaching topics. In Tasmania, the IS curriculum included little technical content, but focused on IS management and strategy. As mentioned above, at the Universities of Tasmania and Canberra, the IS curriculum included a focus on professional development, including interpersonal and group skills. At ADFA, a systems approach was adopted for the IS curriculum. In Western 
Australia, the IS body of knowledge of the four universities with an IS presence reflected local needs and developments, and their links with local industry and professions.

Several state reports referred to use of the ACS accreditation guidelines in the development of IS curricula. Although the ACS guidelines allow considerable flexibility in development of the curriculum, there is a common understanding of topics usually covered. Examples are systems analysis and design, database design and management, project management, managerial and organisational issues, ethical and social implications, professional practice and interpersonal communications. Two of the three ACT universities with an IS program use the ACS guidelines, in combination with specialist knowledge that reflects staff interests and expertise. Programming and software construction was included in the IS curriculum of one university in the Australian Capital Territory, but not in the other two.

South Australian universities indicated that software engineering, computer-supported cooperative work (CSCW), electronic commerce and business information management were key IS teaching topics. The major IS teaching themes in Tasmania were project management, data modelling, data management and electronic commerce, most of which appeared in the ACS guidelines.

The ACT case reported an inconsistency between the topics in the core body of knowledge and IS research methods. Although the core body of knowledge involved construction of artefacts, graduate research students were not exposed to design theory, apart from at the University of Canberra.

\section{Key IS research topics}

Several IS groups identified that their research was applied - for example, ADFA works in the nexus between consultancy and research. The applied nature of much IS research could be seen from the research topics listed for each region.

There was great breadth in the IS research topics studied in Australian universities. To illustrate, the two primary IS research groups at the UniSA had 12 main research foci, while 33 separate research areas were identified at the nine Queensland universities. Six research themes were pinpointed by the IS group at the University of Tasmania.

Despite some differences in the terminology used by different research groups, considerable commonality was found in many of the research topics after analysis. For example, seven of the research foci from the UniSA could be matched to research interests from Queensland universities. Five of the six research themes from the Tasmanian IS were also common to the Queensland research topics. Appendix 12.1 lists the collated research topics identified from all seven regions, showing the common topics. Note, however, that the NSW report identified only a few research topics. 


\section{Summary}

As expected from the diversity in the organisational location of IS teachers, the extent of autonomy of IS groups and the degree programs within which IS teaching took place, IS teaching topics in Australian universities varied enormously. While many of the regions pointed out the difficulty in identifying key IS teaching topics, a number of IS groups taught programs that were consistent with the ACS guidelines. Even though the ACS guidelines allow considerable discretion for curriculum development, many IS groups have a common view of key IS teaching topics from the ACS guidelines.

The topics researched by IS groups were found to be broad and diverse; however, some frequently recurring research topics could be identified that appeared in many of the Australian regions. It is clear that key IS research and teaching topics are influenced by a variety of factors that will vary from one IS group to another, including staff interests and expertise. These factors help account for the breadth of the teaching and research topics seen. Despite the diversity in teaching and research topics, some consensus in key IS topics for both appears possible.

\section{Laws, rules and evidenced guidelines}

Laws, rules and evidenced guidelines is the last component of the core body of knowledge from the first framework construct. Laws or rules are similar to those found in the natural sciences, while evidenced guidelines arise from practice. Little reference was made to laws, rules and evidenced guidelines in the state case studies. The Victorian authors remarked that limited reference to use of an IS theory was made, although the emphasis on interpretive research methods could suggest that agreement exists on a set of evidenced guidelines for research. The Queensland authors reported that no evidence of a theory base was found. The ANU recognised plurality in theory types, while the ACT chapter indicated that little core knowledge from IS could be classified as laws or rules in the way that the natural sciences regarded these theory types. Instead, the authors from the Australian Capital Territory consider that evidenced guidelines are used in IS, which are derived from practice. An example provided was software cost-estimation practices. An additional kind of 'theory' or 'knowledge type', called normative guidelines, was also identified by the same writers. Design theory was seen to be a normative guideline, such as Codd's relational database theory.

\section{Summary}

Although only one region made significant mention of laws, rules and evidenced guidelines for IS, the omission by the others could confirm the view from the ACT authors that laws and rules, as developed in the natural sciences, are largely irrelevant for IS. Instead, the 'more well-grounded, participative style' of 
knowledge type, such as evidenced (and normative) guidelines, is more appropriate in a field that is at the junction of 'science, technology and human and organisational behaviour' (Gregor et al. 2006:190).

\section{Impact of local contingencies versus degree of professionalism}

The second construct in the theoretical framework involves the impact of local contingencies on the IS discipline and its degree of professionalism. Professionalism can be regarded as ways of undertaking IS research and teaching so that there is high task certainty, centralised control of work processes and routinisation of tasks (Whitley 1984b). In such an environment, IS academics will be mutually dependent on each other, and the division of labour for teaching and research sub-tasks might be expected. If IS is not highly professionalised, local contingencies will have a high impact, leading to a considerable variation in the nature of IS research and teaching undertaken in different regions of Australia.

If IS is professionalised, less variation will be seen when comparing the approaches in the regions at one point in time. The degree of professionalism in IS teaching and research will be considered first below, followed by the impact of local contingencies.

\section{Degree of professionalism}

Although few of the reports from the seven Australian regions explicitly considered the degree of professionalism of their IS groups, information could be inferred from other data provided. The professionalism of research and teaching activities will be considered separately, as the circumstances for each differ.

\section{Research}

The authors of the ACT report saw some commonality in the research content undertaken by the IS groups in that region, regardless of whether the research was applied or not. All ACT IS researchers investigated areas that were recognisable as falling within the boundaries of IS, and their fellow researchers had a common understanding of their research.

On the other hand, many IS groups were not able to recognise any commonality in IS research topics. The University of Canberra concluded that the degree of professionalism in research was low, as the IS research of their IS group was largely individual and eclectic. In New South Wales and Tasmania too, the fragmentation and diversity of IS research were seen to limit its professionalism.

While diversity of research topics was certainly seen at the IS group and university level, it is only when the topics were aggregated across the nation, 
and to a lesser extent, across states, that the existence of key research topics could be recognised-as displayed in Appendix 12.1. The many overlapping research topics uncovered in the earlier analysis of research areas from IS groups around Australia suggest that the existence of core research topics that are familiar to other researchers is not unique to ACT universities. It is unsurprising that IS groups and universities considered that there was limited commonality in research topics, given that they had access largely to local evidence only. The issue of whether identifiable core research topics exist in Australian IS is, however, relevant when evaluating whether professionalism occurs in IS research.

Even the ACT authors argued that the wide variation in the research methods used in IS groups in that region acted against the development of professionalism in research, as the routinisation of tasks was not supported. Similarly, the West Australian chapter commented that, because all local universities used many approaches (qualitative and quantitative methods, multiple methods and case studies), the diversity of research methods acted against achieving professionalism in IS research in that state. A number of other universities shared the view that the professionalism of IS research was limited. Limited cooperation in IS research was reported across institutions, particularly in New South Wales. The dispersal of IS groups in 'silos' across universities, particularly within settings in which the researchers are not identifiable as belonging to IS, restricts opportunities for cooperation, and the professionalism of research and teaching.

A further test is the extent to which ACIS committees, reviewers and participants, and AJIS editorial board members, reviewers and readers, mutually recognise one another, one another's topics and one another's research methods, or perceive strangers and strangeness. AJIS has been healthy and, subject to current perturbations associated with the RQF, and discussed shortly, ACIS has also continued to attract healthy attendances. These characteristics are consistent with at least a moderate level of commonality being perceived among community members.

Professionalism requires a common research culture. It is difficult to develop a common culture in research in which groups are fragmented, dispersed, hidden behind non-IS nomenclatures, immersed in the cultures of other disciplines, use a great variety of methods or examine disconnected research topics. Analysis of IS in Australia shows some, but limited, evidence of it being a professionalised discipline from a research perspective.

\section{Teaching}

Those universities that teach research methods in discrete units in postgraduate programs, such as ADFA, help promote the development of professionalism in research through promulgating standard approaches and a common understanding. The operation of IS doctoral programs appears to be another 
mechanism that contributes to increasing professionalism, and links the professionalism of IS teaching to achieving more professionalism in IS research. Inconsistencies, however, between the research methods taught to students in the Australian Capital Territory and the core knowledge of the undergraduate IS curricula delivered in the same region point to a low degree of professionalism. At the time that the ACT chapter was written, research students in two of the three IS groups in the Australian Capital Territory did not have exposure to 'design theory', as they studied research methods with business students; yet the common IS undergraduate curricula in those universities included artefact construction. It seems likely that other Australian IS graduate programs experience the same inconsistency between their undergraduate and research training.

At least for one ACT university, undergraduate IS programs were not designed to prepare students to be IS professionals, but instead aimed to produce 'well-informed users', with an expectation that on-the-job training would develop more uniform work processes within organisations.

The professional skills training offered in some IS programs, however-and referred to earlier - is expected to increase professionalism in the graduates of those programs. Use of the ACS accreditation guidelines for IS curriculum development will also increase professionalism, where adopted.

Within one specific institution, the University of Tasmania, a high to medium level of professionalism was found for IS curriculum and teaching issues, when task certainty, routinisation of activities and division of labour were assessed.

\section{Summary}

Many IS groups commented on the disparity and fragmentation of IS research topics at their university, along with limited collaboration with other IS researchers - attributes that were interpreted as reducing the professionalism of Australian IS research. When, however, the research topics were aggregated across the nation in particular, considerable commonality was displayed, which suggests that core topics exist for Australian IS research. Research methods were also recognised as diverse. The collation of Australian IS research methods across the nation might, however, also reveal a greater uniformity than has been suggested by authors of the individual state chapters.

Mechanisms to increase communication with other IS groups, such as research collaborations across IS groups, joint seminars and appointing staff who are $\mathrm{PhD}$ graduates of another university, will help promote professionalism in research by breaking down silos. Increased communication will also increase the awareness of IS researchers that many of their colleagues in other institutions are researching related issues. 
One university reported a high to medium degree of professionalism for its IS teaching, and a low to medium degree of professionalism in its IS research. As reported earlier, the same university IS group has recently merged with a school of computing. This and other recent and future restructuring of IS groups in Australian universities could reduce the professionalism of IS research and teaching. A range of pressures were identified that acted to promote or reduce the professionalism of teaching, which operated at the undergraduate or graduate level. Given the limitations of the data in the state reports, however, the professionalism of Australian IS teaching was difficult to determine.

\section{Impact of local contingencies}

The following discussion sets out the impact of local contingencies reported by the regions in three sections: on research, on teaching and on both.

\section{Research}

A range of local issues were considered to influence IS research. Few joint research projects were conducted in Western Australia, as a result of little interaction and collaboration among the universities there. In South Australia and Tasmania, the development of strategic relationships with large corporations was difficult as few large companies were present in those states or, where they were present, the head office was located elsewhere. One result of this characteristic has been that research in both states has investigated phenomena in small and medium-sized enterprises. Another characteristic mentioned by several universities, including the UniSA, was that $\mathrm{PhD}$ numbers were restricted by the availability of supervisors.

In Queensland, the nature of research conducted in IS groups was seen to be influenced by the competencies and interests of academic research leaders more than geography. There was, however, some evidence of a deliberate policy to focus on global issues in IS in that state rather than on those that were more local.

\section{Teaching}

The nature of local contingencies that affected IS teaching issues was found to be highly variable.

One local contingency pointed to in South Australia was a perceived limited interest in IS. This was accounted for in two ways. The first was the state's interest in resources, agriculture and defence. The second reason given was that there was no single state minister with responsibility for ICT; it was shared among six ministers. A comparison was made of South Australia's interest in IS with that in Western Australia, a neighbouring state. Despite some similarities between the two states, all four of the West Australian universities that offered 
IS also offered an IS degree, contrasting with South Australia, where only one of its three universities offered an IS degree.

In South Australia, the relationship between the IS and computing curricula in one university was described as being 'finely focused' as a consequence of the recent amalgamation of the two disciplinary groups. In South Australia as well, the content of IS teaching was influenced by local and interstate industries, and by the fact that defence was the major ICT industry in Adelaide. At ADFA in the Australian Capital Territory, the defence services encouraged study in IS and computing to at least second year in a degree, which helped increase enrolments.

In Tasmania, local contingencies were found to have a low to medium impact on curriculum and teaching.

It was reported in the Victorian chapter that local industry had little impact on IS curricula. National influences were seen to have had a greater role than the local community and industry in the development of Victorian IS curricula. The Victorian chapter identified that a cyclical demand for IS courses had influenced IS enrolment most. For example, in the late 1990s, IS had strong enrolments in Australian universities, but this trend had reversed by 2004. Declining IS enrolment was identified by many state reports including that from New South Wales, and also by the international commentators in the theoretical framework chapter. This pressure then is a global one, and not local.

\section{Impact on research and teaching}

A number of local contingencies influenced IS research and teaching. Geography was referred to by the more remote states as a contingency that was able to act on teaching and research. The remote location of West Australian IS groups resulted in reliance on local industry and international connections, rather than on those in the eastern states of Australia. Western Australia also referred to local and state political pressures, which could have an impact either on teaching or research. The Tasmanian interviewees also mentioned political pressures. The South Australian government outsourced all ICT to interstate or offshore locations, which was seen to impact on the IS groups within the state, with ramifications for teaching and research.

Local contingencies had an impact on IS in the three universities in the Australian Capital Territory to a moderate degree. The position of the IS groups in the university structure influenced the units taught and the nature of the research. The business orientation of the IS group in one ACT university influenced teaching and research differently than that for the IS group in another university with a primary role to educate defence force personnel.

The NSW case concluded that local contingencies were restricted in their application, and were not state wide. Examples given were variable and included 
organisational politics, the nature of nearby employers and competitors, support from a large local industrial organisation in Wollongong and faculty rules at the University of Sydney.

In Queensland, the IS leader was sometimes seen to determine the nature of the curriculum and research, rather than both being determined by local community characteristics. An example was provided of an IS group at a Queensland university where the curriculum and research direction changed from a focus on soft systems to technical issues when the IS leader changed. The Queensland case commented that local contingencies had high impact.

At Charles Sturt, a regional university in New South Wales, the visibility of IS has been linked to the cross-campus structure of that university, and to university politics.

\section{Summary}

Local, and therefore different, contingencies had acted on research and teaching. Some local contingencies had impacted on the nature of IS research and teaching in Australia, including geography, political pressures and organisational structure.

\section{Linking the degree of professionalism and the impact of local contingencies}

The Tasmanian chapter reported that local contingencies appeared to have a low to medium impact on curriculum and teaching, while also having a high to medium impact on research issues. The reverse, however, appeared to be the case for the degree of professionalism, in that curriculum and teaching issues were seen as having a high level of professionalism while research activities were assessed as low to medium. As IS curricula in Victoria have been influenced more by national forces than by local ones, this characteristic suggests that Victorian universities have achieved a degree of professionalism in teaching.

\section{Australian responses to reduced ICT enrolments}

Since the 'dotcom implosion' of about 2000, enrolments in IS courses have decreased substantially. This section consolidates information about the patterns following that phenomenon that are evident in the various state reports.

\section{Changes to organisational arrangements}

Across universities in all states there was evidence that IS groups had restructured, or were planning to do so. In Queensland, for example, this was the case with every one of the 11 universities surveyed.

In some instances, IS groups that had achieved administrative independence from business faculties were subsumed back within business after the decline 
in IS enrolments. In other instances, administratively separate IS groups lost their independent status, instead being recognised less formally as IS groups within a more generic ICT school or faculty. The state report on Tasmania also refers to pressure on computing to take over IS teaching areas. Almost without exception, the planned restructuring in Australian universities involved a reduction in staffing levels within IS groups.

\section{Changes to IS curriculum}

This downsizing was accompanied invariably by a rationalisation of ICT curriculum offerings. It is clear, however, that the consequent planned reduction in IS subjects is far from uniform across Australia. In one reported Victorian university, for example, the process of rationalising the ICT curriculum led to a strengthening of the relative position of IS. In such cases, senior ICT academics have taken the strategic view that, in an Australian context, future job opportunities will favour ICT graduates with a good grasp of the organisational and application context, as well as the technology - that is, IS graduates. A similar positive view for IS is proposed by David Wilson in his response to the Underwood and Jordan report on IS in New South Wales. The latter NSW authors had commented that, because IS was fragmented, a continued decline in undergraduate enrolments would weaken the position further.

\section{Changes in IS research}

The decline in the range of subjects in the IS curriculum does not appear to have been matched by a comparable decline in IS research. While the impending reduction in the number of IS academics could be expected to lead to a reduction in IS research output from Australian universities, a more recent focus on research quality has been reported. This latter development was driven by the proposed introduction of the RQF in the Australian university sector. The planned RQF and its potential wider impact on IS in Australian universities are discussed more fully in the next section of this chapter.

\section{Summary}

The recent reduced student enrolments led to changes in the organisational location of IS groups in many universities, reduced staffing and rationalisation of the ICT curriculum. In some IS groups, these changes were used strategically to strengthen the position of IS in comparison with related disciplines. Reduced student enrolments appeared not to have impacted on the quality of Australian IS research.

\section{The RQF and its impact}

The RQF was a federal Liberal government initiative planned for implementation in Australian universities in 2008. It can be viewed as an attempt to increase the 
quantity and, in particular, the quality and impact of research in Australian universities.

A more cynical view of the RQF was that its purpose was to further concentrate funding in those institutions, and in those disciplines and multi-disciplinary centres, that had achieved maturity and already had substantial research resources.

Under the provisions of the RQF, an assessment was to be made of the research produced by research groups within each Australian university. Based on this assessment, the Australian government was to distribute research funding to the universities. It seemed likely that the RQF would have more than just a financial influence; there was a likelihood that the RQF rating of individual Australian universities would be viewed as a significant indicator of the relative status of each university. The state reports each touch on various aspects of the proposed RQF and its impact on IS in Australian universities. The incoming Labor government announced, in December 2007, the abandonment of the RQF; however, an alternative mechanism for evaluating Australian university research output was foreshadowed.

\section{Impact on the long-term viability of IS conferences}

A feature of the RQF was that researchers would receive little weight for publications in conference proceedings; much greater recognition was to be given for publication in research journals.

On the basis of the planned RQF, there is evidence that the low recognition accorded by the framework for publishing research in conference proceedings was leading to a change in the choice of publication outlets by Australian IS researchers. Since the RQF was to assess research publications from the previous three years as evidence of research productivity, IS researchers were seeking outlets for their research results in journals rather than via conferences. It could be supposed that the characteristics of any replacement for the RQF will result in some new reactive behaviour by Australian IS academics.

\section{Summary}

Researchers considered that the RQF would have an important influence on IS in Australian universities. One anticipated consequence was reduced participation in IS conferences by Australian IS researchers. In light of the observed impact of the proposed RQF, it is predicted that its foreshadowed replacement will also have the effect of changing aspects of the IS discipline in Australian universities.

\section{Limitations and future research}

A feature of the study, commented on by researchers in the individual Australian states, was that the evidence presented represented no more than a snapshot of 
the situation during a period of major perturbation in the IS academic discipline in Australia. Although analysis of the aggregated data has sought to detect some significant trends, there is a clear need to replicate the study over time. At a time of major change, threats and opportunities multiply; the success of responses to these will become apparent in future studies.

\section{Conclusions}

The meta-analysis chapter consolidated and interpreted the data from earlier chapters in this monograph, to set out an overview of the IS academic discipline in Australian universities, using the theoretical framework developed for the investigation.

Although IS has broad (but not universal) acceptance in Australian universities as a teaching and research program, considerable variation was noted in staff and student numbers from one IS group to another, and in the staff/student ratio. The organisational location and independence of the IS groups also varied, sometimes being fragmented across departments and faculties, although most were located in science or business. This fragmentation, and the pressure for restructuring placed on IS groups more recently as student enrolments have declined, has eroded autonomy for IS in Australian universities. Despite the rapid growth in IS professorial appointments in Australian universities between 1998 and 2004, and the strongly identified IS programs in some universities, reduced opportunities for control of critical rewards have been seen since that time. Diversity of research methods and standards, and of teaching methods and standards, was reported.

Australian IS staff considered that the discipline did not have a unique symbol set, which could help to explain the diversity in the organisational location of IS groups. Without a recognised unique symbol set, there are few limitations on other disciplines to deliver IS teaching programs or undertake IS research. Teaching topics varied broadly, although many IS groups delivered programs that were consistent with the ACS guidelines. Although IS research topics were viewed as being very diverse across the universities, analysis of topics across the states and, in particular, across Australia, revealed considerable commonality. The consensus reached about IS teaching, and in particular research topics, could offer some potential for the future development of an IS symbol set. One barrier that would need to be overcome is the perception from Australian IS university academics that IS topics studied by one group have little in common with those examined by another. Increased mechanisms for communication among Australian IS researchers and lecturers might reduce this obstacle and limit silos. Having core topics for Australian IS research and increasing focus on high-quality journal publications brought about through the RQF process could act to increase the professionalism of Australian IS research. Conversely, recent restructuring of 
IS groups in Australia could work to reduce the professionalism of IS research and teaching.

The study findings suggest that laws and rules, as understood by the natural sciences, are not appropriate for the IS discipline. Evidenced guidelines and normative guidelines are more suitable. This recognition of the most relevant theory types for the discipline could signal increasing maturity for the IS discipline in Australia, rather than having IS apply less suitable theory types to emulate high-status disciplines.

Although a range of local pressures acted on research and teaching, there were some signs of increasing professionalism, including Victorian IS curricula responding to global influences, as well as the responses of Australian IS researchers to the proposed $\mathrm{RQF}$ process. Reduced student enrolments in recent times resulted in some organisational relocation of IS groups, changes to the ICT curriculum and reduced IS staff numbers, but these outcomes had not hampered the quantity or quality of IS research.

Just as the diversity found in different aspects of IS in Australian universities implied that some groups were more successful than others across a range of criteria, including publication output, success in gaining external funding, reduced staff/student ratios and group autonomy, some IS groups were able to strengthen their position in comparison with other ICT disciplines during recent organisational restructuring. The ANU and some Victorian IS groups stood out on several criteria, as reported in the study. Although beyond the scope of this current volume, it is interesting to conjecture on possible reasons for these differences. The historical origins of some of the universities in which the IS groups appear might offer some explanation, as might the nature of the leadership of IS groups. Certainly, the achievements of key Australian IS leaders, as reported in this monograph, have helped some groups gain greater access to resources and status.

With the reduced student enrolment in IS programs in universities around the world in recent years, it would be easy to dwell on this phenomenon, as data collection and analysis took place at one time during this period. Yet this study also examined indirectly the achievements to date of Australian IS as a discipline, in addition to the relative change to that position in recent times.

The framework's first construct referred to mechanisms of control and the core body of knowledge. Although achievements for mechanisms of control were mixed, considerable progress had been made towards this component in the past decades in IS, including the number of professorial appointments, the inclusion of IS representation on ARC panels and the establishment and recognition of a national IS journal, a national conference and ACPHIS. Of the four components that make up the core body of knowledge, acknowledgement needs to be made that key research topics have been established, and ACS teaching topics have 
been developed and are recognised. The framework's second construct referred to the impact of local contingencies versus the degree of professionalism. Local contingencies were found to have impacted on the degree of professionalism; however, the study was not able to confirm that the two components were inversely related.

One broad aim of this current investigation was to consider whether IS in the Australian context should be labelled a discipline or a field, using the definitions of both reported in Chapter 3 and restated below for the reader's convenience. The contributions of significant international IS researchers to this study suggest that the answer to this question will be one that is common to IS groups outside Australia.

If a discipline is defined as

a body of knowledge, definitions, and concepts built up over a long period and receiving consensus recognition by scholars; theories which interrelate the concepts and provide explanations of observed phenomena and permit predictions from them; and well established research methodologies (Tardif 1989)

the findings of the current investigation from IS academics in Australian universities demonstrate that IS cannot satisfy this definition of a discipline. Although the types of theory that are appropriate for IS have been distinguished (see Gregor et al. 2006), few of the theories so developed interrelate the concepts, provide explanations of observed phenomena and permit predictions from them. Further, using this definition of a discipline and the nature of IS theory discussed in this study, as distinct from the laws and rules found in some other disciplines, it appears that IS has some way to go to become a discipline. Analysis on a national scale revealed that core IS research topics existed in Australia; however, this characteristic did not yet have consensus recognition by individual researchers or groups. Also, since the first Australian IS professor was appointed only just more than two decades ago, such a period is insufficient to have allowed IS to have developed into a discipline. If IS is not then a discipline, can it be considered as a field, where a field is

an area of knowledge and learning which is not yet accepted as a discipline. Fields of study tend to be more recent areas of scholarship with somewhat fuzzy boundaries; significant numbers of concepts within them are open to debate; and researchers and scholars in the area tend to draw heavily on old-established disciplines for their methodologies and conceptualisations. (Tardif 1989)

Certainly, it appears that IS cannot be accepted as a discipline as yet and it is a recent area of scholarship. This study indicates that the boundaries of IS are fuzzy, and its concepts are debated; for example, there is no accepted symbol 
set that would enable common terms to be used to represent concepts. Although IS has a history of borrowing from its reference disciplines for its methodologies and 'conceptualisations', this study has revealed some signs that IS is starting to reflect on both that are of particular relevance, as is seen in the recent focus on 'design science' (see Hevner et al. 2004; Gregor and Jones 2007). Overall, this study of IS in Australian universities provided evidence that IS is more like a field than a discipline.

\section{Select bibliography}

Bryant A. 2006, Thinking 'Informatically': A New Understanding of Information Technology, Communications and Technology, Edwin Mellon Press, Lewiston, New York.

Dixon-Woods, M., Agarwal, S., Jones, D., Young, B. and Sutton, A. 2005, 'Synthesising qualitative and quantitative evidence: a review of possible methods', Journal of Health Services Research \& Policy, vol. 10, no. 1, pp. $45-53$.

Gable, G. 2006, 'The information systems discipline in Australian universities: a contextual framework', Australasian Journal of Information Systems, vol. 14, no. 1, pp. 103-22.

Gregor, S. and Jones, D. 2007, 'The anatomy of a design theory', Journal of the Association of Information Systems, vol. 8, no. 5, pp. 312-35.

Gregor, S., Lewis, E. and McDonald, C. 2006, 'Case study: the state of information systems in Australian Capital Territory universities', Australasian Journal of Information Systems, vol. 14, no. 1, pp. 177-92.

Hevner, A. R., March, S. T., Park, J. and Ram, S. 2004, 'Design science in information systems research', MIS Quarterly, vol. 28, no. 1, p. 75.

Marginson, S. and Considine, M. 2000, The Enterprise University: Power, Governance, and Reinvention in Australia, Cambridge University Press, Cambridge, UK.

Mingers, J. and Stowell, F. (eds) 1997, IS: An Emerging Discipline, McGraw-Hill, London.

Tardif, R. (ed.) 1989, The Penguin Macquarie Dictionary of Australian Education, Penguin, Ringwood, Victoria, Australia.

Whitley, R. 1984a, 'The development of management studies as a fragmented adhocracy', Social Science Information, vol. 23, no. 4-5, pp. 775-818.

Whitley, R. 1984b, The Intellectual and Social Organization of the Sciences, Clarendon Press, Oxford, UK. 
The Information Systems Academic Discipline in Australia

\section{Appendix 12.1: analysis of IS research topics by state}

\section{Table A12.1 Collated IS research topics reported, by state}

\begin{tabular}{|c|c|c|c|c|c|c|c|c|}
\hline Topic & Stat & & & & & & & Total \\
\hline Anti-terrorist management & & & ACT & & & & & 1 \\
\hline Business intelligence & & & & & & Qld & & 1 \\
\hline Business logistics/transport modelling & & & & Tas & WA & & & 2 \\
\hline Business process modelling & Vic & & & Tas & & Qld & & 3 \\
\hline Compliance monitoring systems & & & & & WA & & & 1 \\
\hline Computational intelligence & Vic & & & & & & & 1 \\
\hline Conceptual modelling/ontology/relational ontology & Vic & & ACT & & WA & Qld & & 4 \\
\hline Data acquisition & & SA & & & & & & 1 \\
\hline Data quality & & SA & & & & Qld & & 2 \\
\hline Data warehousing/data mining and informatics & Vic & SA & & & & Qld & & 3 \\
\hline Databases & & & & & WA & Qld & & 2 \\
\hline $\begin{array}{l}\text { Decision support systems/intelligent and collaborative } \\
\text { systems }\end{array}$ & Vic & SA & ACT & & WA & Qld & NSW & 6 \\
\hline Distributed simulation & Vic & & & & & & & 1 \\
\hline E-commerce education & Vic & & & & & & & 1 \\
\hline E-commerce/e-business/electronic markets & Vic & SA & & & WA & Qld & & 4 \\
\hline E-forensics & & & & Tas & & Qld & & 2 \\
\hline E-government/e-law/legal systems in IS & Vic & & ACT & & WA & & & 3 \\
\hline E-research & & & ACT & & & & & 1 \\
\hline Enterprise resource planning/enterprise systems & Vic & & & & & Qld & & 2 \\
\hline Ethics, privacy and censorship & Vic & & ACT & & & & & 2 \\
\hline Gender and IT & Vic & & & & & Qld & & 2 \\
\hline Grid supercomputing & & & & & WA & & & 1 \\
\hline Health informatics & Vic & & ACT & Tas & WA & Qld & & 5 \\
\hline Information management & Vic & SA & & & & & & 2 \\
\hline Interoperability standards & & SA & & & & & & 1 \\
\hline IS evaluation & & & & & WA & & & 1 \\
\hline IS in the construction industry & & & & & WA & & & 1 \\
\hline IS methodologies & & SA & & & WA & Qld & & 3 \\
\hline IS/IT education/e-learning & Vic & SA & ACT & & WA & Qld & & 5 \\
\hline IS/IT governance & Vic & & ACT & & & Qld & & 3 \\
\hline IT professional services/consulting & & & & & & Qld & & 1 \\
\hline IT sourcing & & & & & & Qld & & 1 \\
\hline IT/IS management & Vic & & & & WA & Qld & & 3 \\
\hline Knowledge management & Vic & SA & & & WA & Qld & & 4 \\
\hline Mathematics and statistical analysis & Vic & & & & & & & 1 \\
\hline Multimedia & & & & & & Qld & & 1 \\
\hline Packaged software & & & & & & Qld & & 1 \\
\hline Programming methodology & & & & & & Qld & & 1 \\
\hline Project management & Vic & & ACT & & & & & 2 \\
\hline Requirements engineering & Vic & & & & & Qld & & 2 \\
\hline Risk management & & & ACT & & & & & 1 \\
\hline Rural IS & & & & & & Qld & & 1 \\
\hline
\end{tabular}


Table A12.1 Collated IS research topics reported, by state

\begin{tabular}{|c|c|c|c|c|c|c|c|c|}
\hline Topic & Stat & & & & & & & Total \\
\hline Security & Vic & SA & & Tas & & Qld & & 4 \\
\hline Semantic webs & Vic & & & & & & & 1 \\
\hline Socio-organisational systems/human factors in IS & & SA & & & WA & Qld & & 3 \\
\hline Soft systems & & & & & WA & & & 1 \\
\hline Software engineering/software quality and assurance & Vic & & & & & Qld & NSW & 3 \\
\hline Strategic IS & Vic & & ACT & Tas & WA & Qld & & 5 \\
\hline Supply-chain management & Vic & & & & & & & 1 \\
\hline Systems development & Vic & & & & & Qld & & 2 \\
\hline Systems modelling/simulation & & & & & & Qld & & 1 \\
\hline Technology adoption and impact & Vic & & ACT & & WA & & & 3 \\
\hline Theoretical foundations & & & ACT & & & & & 1 \\
\hline Tools for human thinking & & & ACT & & & & NSW & 2 \\
\hline $\begin{array}{l}\text { Usability design/human-computer interaction/end-user } \\
\text { issues }\end{array}$ & Vic & & ACT & & & Qld & & 3 \\
\hline Virtual communities/virtual behaviour & & & ACT & & WA & & & 2 \\
\hline Web services & & & & & & Qld & & 1 \\
\hline Workflow & & & & & & Qld & & 1 \\
\hline
\end{tabular}

Note: Occurrence recorded for each state, not frequency.

Table A12.2: Frequency and proportion of common IS research topics reported, by state

\begin{tabular}{l|l|l}
\hline Proportion of common IS research topics & Count & $\%$ \\
\hline Topics researched in 1 state & 27 & 47 \\
\hline Topics researched in 2 states & 13 & 22 \\
\hline Topics researched in 3 states & 10 & 17 \\
\hline Topics researched in 4 states & 4 & 7 \\
\hline Topics researched in 5 states & 3 & 5 \\
\hline Topics researched in 6 states & 1 & 2 \\
\hline Total topics & $\mathbf{5 8}$ & $\mathbf{1 0 0}$ \\
\hline
\end{tabular}


The Information Systems Academic Discipline in Australia

Table A12.3: Most-popular IS research topics reported in Australian states

\begin{tabular}{l|l}
\hline Topic & No. of states \\
\hline $\begin{array}{l}\text { Decision support systems/intelligent and collaborative } \\
\text { systems }\end{array}$ & 6 \\
\hline Strategic IS & 5 \\
\hline IS/IT education/e-learning & 5 \\
\hline Health informatics & 5 \\
\hline Security & 4 \\
\hline Knowledge management & 4 \\
\hline E-commerce/e-business/electronic markets & 4 \\
\hline Conceptual modelling/ontology/relational ontology & 4 \\
\hline Business process modelling & 3 \\
\hline Data warehousing/data mining and informatics & 3 \\
\hline E-government/e-law/legal systems in IS & 3 \\
\hline IS methodologies & 3 \\
\hline IS/IT governance & 3 \\
\hline IT/IS management & 3 \\
\hline Socio-organisational systems/human factors in IS & 3 \\
\hline Software engineering/software quality and assurance & 3 \\
\hline Technology adoption and impact & 3 \\
\hline Usability design/human-computer interaction/end-user & 3 \\
issues & \\
\hline
\end{tabular}

Note: Occurrence recorded for each state, not frequency. 